\title{
Emergency peripartum hysterectomy- a study in tertiary care centre and medical college in Hubli, North Karnataka, India
}

\author{
Sahaja Kittur*, Swetha D.
}

Department of Obstetrics \& Gynaecology, Karnataka Institute of Medical Sciences, Hubli, Karnataka, India

Received: 08 January 2016

Accepted: 01 March 2016

\section{*Correspondence:}

Dr. Sahaja Kittur,

E-mail: drsahajakittur@rediffmail.com

Copyright: (C) the author(s), publisher and licensee Medip Academy. This is an open-access article distributed under the terms of the Creative Commons Attribution Non-Commercial License, which permits unrestricted non-commercial use, distribution, and reproduction in any medium, provided the original work is properly cited.

\begin{abstract}
Background: Post-partum haemorrhage is a significant cause of maternal mortality and morbidity. The objective of the study was to evaluate the incidence, predisposing factors \& associated complications and outcome of emergency peripartum hysterectomy.

Methods: It is a prospective analysis of emergency peripartum hysterectomy conducted at tertiary care centre at Karnataka Institute of Medical Sciences, Hubli, Karnataka, India between June 2013 to December 2015. Age, parity, traumatic or atonic PPH, risk factors, complications were all studied in detail and analysed.

Results: 43 women underwent peripartum hysterectomy among 28,620 deliveries, accounting to an incidence of $0.15 \%$. Incidence of subtotal hysterectomy after caesarean delivery was higher as compared to vaginal deliveries. The common indications were uterine atony $(46.5 \%)$, uterine rupture of scared and unscared uterus $(44.1 \%)$, placenta previa of major degree and sepsis (6.9\%). Post-operatively 13 patients developed DIC (30.2\%), 5 patients developed febrile illness $(11.6 \%), 5$ patients of ruptured uterus experienced injury to the bladder (11.6\%). Maternal mortality in this study was $13.9 \%$.

Conclusions: Hysterectomy is a lifesaving procedure to control postpartum hemorrhage, but is associated with significant maternal morbidity and mortality. Uterine atony, uterine ruptures, also due to prior caesarean delivery, placenta previa were identified as risk factors. The incidence in this part of Karnataka was found to be significantly high due to referral cases from neighboring 5 government district hospitals. Hence only proper awareness, timely referral and correction of anemia are the key factors to be addressed to this part of the state.
\end{abstract}

Keywords: Peripartum hysterectomy, PPH, Placenta previa, Rupture uterus

\section{INTRODUCTION}

Peripartum hysterectomy is defined as hysterectomy performed at the time of or within 24 hours of delivery. Emergency peripartum hysterectomy is most commonly performed to arrest or prevent haemorrhage from intractable uterine atony, abnormal placentation or trauma to genital tract. ${ }^{1-6}$ Other indications are uterine rupture, uterine extension, and post-partum uterine infection. Conservative measures to arrest bleeding are initially tried before considering EPH. The measures include uterotonic drugs, haemostatic compression sutures, stepwise uterine, ovarian artery ligation or bilateral internal iliac artery ligation., ${ }^{5,6,8}$ Conservative management is of particular importance in patients who are haemodynamically stable. Conservative measures should be employed with the goal of avoiding the morbidity and sterilization that comes with hysterectomy. The major complications of hysterectomy include increased blood loss, performed for haemorrhage that frequently is torrential and greater risk of urinary tract damage

Uterine atony, most commonly found in prolonged, augmented and/or obstructed labour, such uteruses respond poorly to oxytocic. The majority of these cases 
occur at the time of caesarean section for dystocia or cephalopelvic disproportion. Uterine rupture within prior caesarean section scar, if haemorrhage cannot be controlled hysterectomy is necessary. ${ }^{7}$ Traumatic rupture following instrumental delivery, obstructed labour, inversion of uterus, induced labour is also possible. Secondary post-partum haemorrhage secondary to retained products and sepsis may rarely require hysterectomy.

\section{METHODS}

A prospective analysis of all patients who delivered during the period June 2013- December 2015 in Karnataka institute of Medical Science, Hubli, India either by vaginal delivery or caesarean sections.

\section{Inclusion criteria}

- Patients who suffered severe post-partum haemorrhage and did not respond to conservative management, leading to emergency peripartum hysterectomy.

- Patients with ruptured uterus of both scared and unscared uterus which could not be repaired, leading to emergency peripartum hysterectomy.

\section{Exclusion criteria}

- Hysterectomies performed for gynaecological cause were excluded from the study.

Data abstracted included demographic data - age, parity, mode of delivery, prior caesarean sections, presence of placenta previa, presence of uterine rupture \& uterine atony as a cause of PPH and traumatic PPH. The postsurgical complications, duration of hospital stay, maternal mortality \& morbidity were recorded. Descriptive analyses were carried out to summarize relevant variables.

\section{RESULTS}

The estrogen level in hCG day (pmol/l) in long agonist Between 2013 June - December 2015, there were 28,620 deliveries. 43 underwent emergency peripartum hysterectomy, yielding to an incidence of $0.15 \% .16$ patients underwent emergency peripartum hysterectomy following vaginal delivery, among whom 2 patients had instrumental delivery and 27 following caesarean section. Age distribution among the patients with underwent hysterectomy revealed that 1 patient was <20years of age $(2.3 \%), 37(86 \%)$ were between the age group of 21-30 and $5(11.6 \%)$ were of age group 31-40. Parity distribution showed that 5 were primipara $(11.6 \%)$, parity of 2 were $20(46.5 \%)$ and parity of 3 were $13(30.2 \%)$ and beyond parity 3 were $4(9.3 \%)$. The table below shows the age-parity distribution and mode of delivery.
27 patients in the study underwent caesarean sections, among them 11 patients were prior 1 LSCS (29.4\%), 3 patients were prior 2 LSCS $(5.88 \%) .8$ (18.6\%) patients had placenta previa, $1(2.3 \%)$ patient presented with a combination of rupture uterus and placenta previa, underwent caesarean section, $1(2.3 \%)$ patient presented with placenta previa and abruption placenta. The incidence of hysterectomy did not increase significantly in women with parity of 3 and beyond.

Table 1: Demography.

\begin{tabular}{|c|c|c|}
\hline & $\begin{array}{l}\text { Emergency } \\
\text { hysterectomy }\end{array}$ & $\%$ \\
\hline \multicolumn{3}{|l|}{ Age (years) } \\
\hline$<20$ & 01 & $2.3 \%$ \\
\hline $21-30$ & 37 & $986 \%$ \\
\hline $31-40$ & 5 & $11.6 \%$ \\
\hline \multicolumn{3}{|l|}{ Parity } \\
\hline 1 & 5 & $11.6 \%$ \\
\hline 2 & 20 & $46.5 \%$ \\
\hline 3 & 13 & $30.2 \%$ \\
\hline$>3$ & 4 & $9.3 \%$ \\
\hline \multicolumn{3}{|c|}{ Mode of delivery } \\
\hline Vaginal & 14 & $32.5 \%$ \\
\hline Caesarean & 27 & $62.7 \%$ \\
\hline Instrumental & 2 & $4.65 \%$ \\
\hline
\end{tabular}

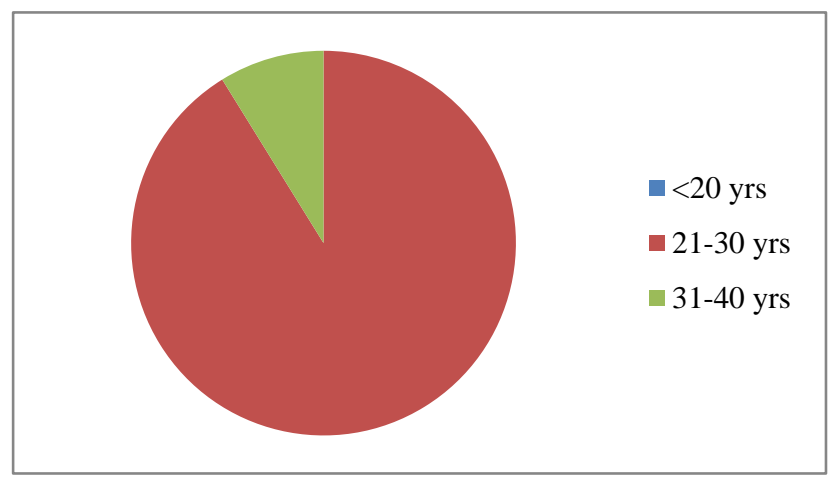

Figure 1: Age distribution in the study.

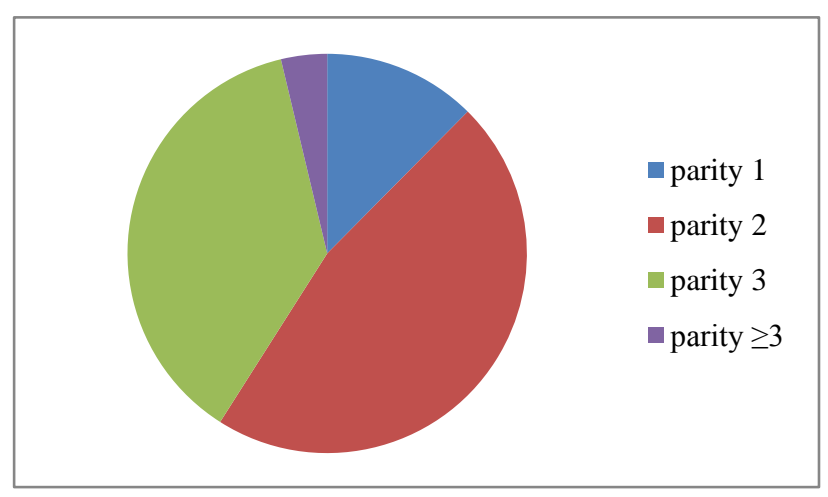

Figure 1: Parity distribution. 


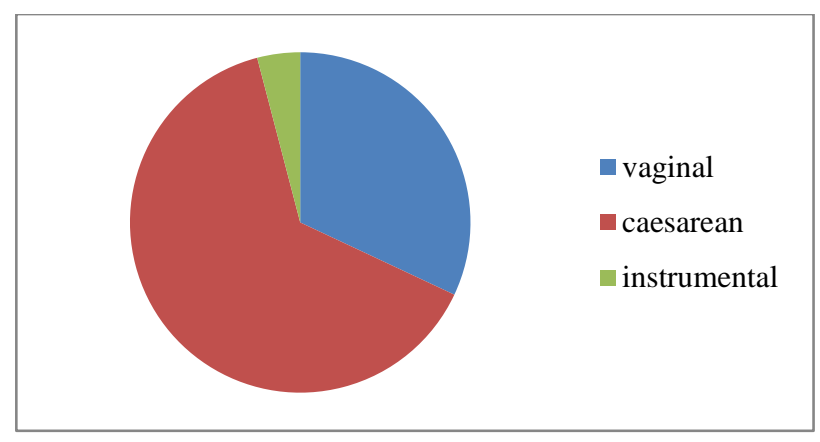

Figure 3: Mode of delivery.

The most common indications out of the incidence was atonic PPH, noted in 20 patients $(46.5 \%)$, following vaginal delivery were $8(18.6 \%)$, following caesarean section were 12 (27.9\%). Indication for rupture uterus were $19(44.1 \%), 9(20.9 \%)$ following rupture of an unscarred uterus. $10(23.2 \%)$ following rupture of scarred uterus. Due to secondary post- partum haemorrhage were $3(6.9 \%)$. Among the patients who developed secondary postpartum haemorrhage, $2(4.65 \%)$ patients presented with bleeding per vagina on day 10 and day 15 respectively, retained bits of placenta with sepsis was found to be the cause of secondary PPH and 1 (2.3\%) patient had atonicity of uterus following dilatation and curettage performed for retained bits of placenta. Acute inversion of uterus $(2.3 \%)$ was the cause for emergency peripartum hysterectomy in $1(2.3 \%)$ patient.

Table 2: Risk factors.

\begin{tabular}{|lll|}
\hline Risk factor & $\begin{array}{l}\text { Emergency } \\
\text { hysterectomy }\end{array}$ & $\%$ \\
\hline Caesarean section & 27 & \\
\hline Prior no LSCS & 13 & $30.2 \%$ \\
\hline Prior 1 LSCS & 11 & $25.5 \%$ \\
\hline Prior 2 LSCS & 3 & $6.9 \%$ \\
\hline Prior 3 LSCS & 0 & \\
\hline Placenta previa & & $18.6 \%$ \\
\hline Yes & 8 & $81.3 \%$ \\
\hline No & 35 & \\
\hline Parity & 13 & $30.2 \%$ \\
\hline 3 & 4 & $9.3 \%$ \\
\hline$>3$ & & \\
\hline
\end{tabular}

8 patients who had placenta previa - (a) one patient with previous history of caesarean section underwent LSCS for placenta previa type IIa during index pregnancy, intraoperatively discovered to have placenta accreta. She suffered severe blood loss due to intractable bleeding from the placental bed and was managed by emergency peripartum hysterectomy and massive blood transfusion; (b) one patient with no history previous surgeries underwent caesarean section during index pregnancy for central placenta previa, underwent emergency peripartum hysterectomy for uncontrolled bleeding from the placental bed. Bilateral internal iliac artery ligation was performed, but she succumbed to death intra-operatively due to massive blood loss; (c) one patient with previous history 2 LSCS underwent caesarean for central placenta previa underwent hysterectomy for bleeding from placental bed, died on post-operative day 1 due to DIC; (d) one patient presented with placenta previa type III and abruption placenta, underwent LSCS and intraoperatively developed atonicity of uterus and underwent hysterectomy; (e) One patient with placenta previa type II and previous history of caesarean section, presented in shock to the hospital, was found to have ruptured uterus. Immediately was taken up for emergency hysterectomy and massive blood transfusion was started. Patient died on post-operative day 4 due to disseminated intravascular coagulation; (f) 3 patients with placenta previa underwent hysterectomy due to atonic postpartum haemorrhage.

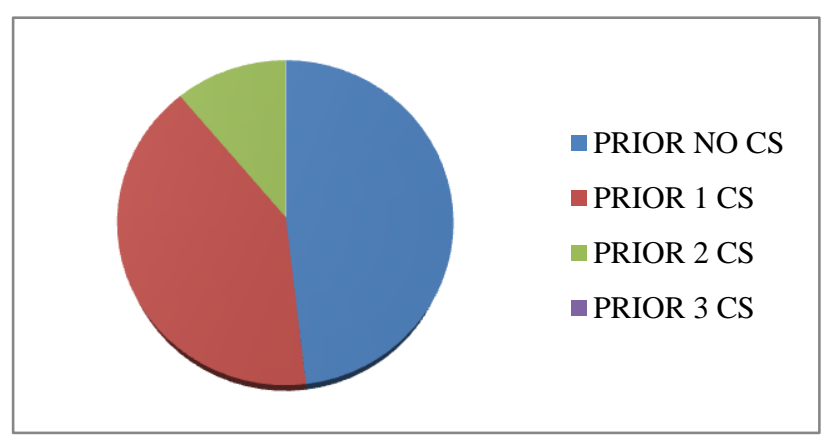

Figure 4: History of previous caesarean section.

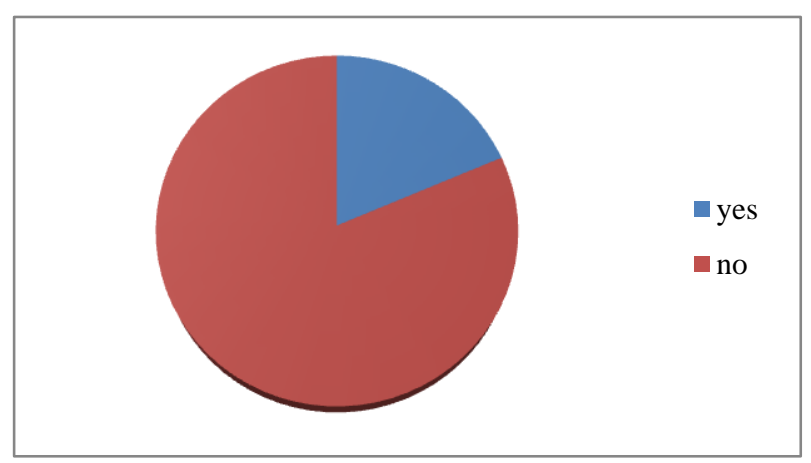

Figure 5: Presence of placenta previa as a risk factor.

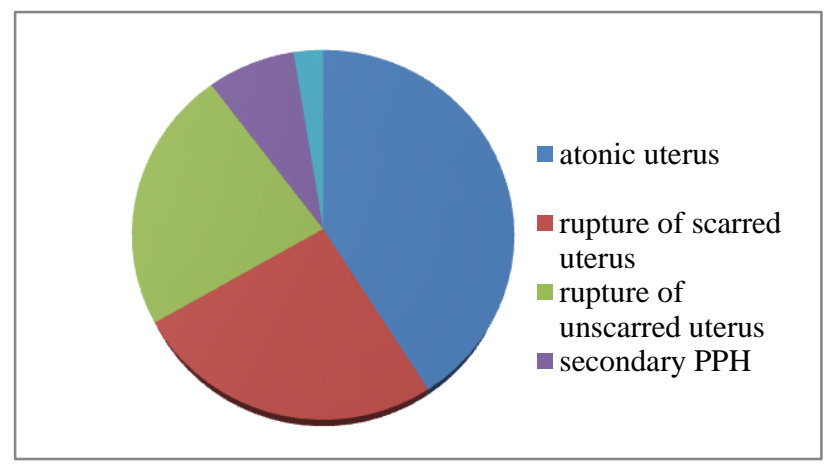

Figure 6: Indication for emergency peripartum hysterectomy. 
Table 3: Indications for emergency peripartum hysterectomy.

\begin{tabular}{|lll|}
\hline Indication & $\begin{array}{l}\text { Emergency } \\
\text { hysterectomy }\end{array}$ & $\%$ \\
\hline Atonic uterus & 20 & $46.5 \%$ \\
\hline Rupture of scarred uterus & 10 & $23.2 \%$ \\
\hline $\begin{array}{l}\text { Rupture of unscarred } \\
\text { uterus }\end{array}$ & 9 & \\
$\begin{array}{l}\text { ( spontaneous rupture) } \\
\text { a)primigravida } \\
\text { b) multigravida }\end{array}$ & 1 & $20.9 \%$ \\
\hline Secondary PPH & 8 & $6.9 \%$ \\
\hline $\begin{array}{l}\text { Acute inversion of } \\
\text { uterus }\end{array}$ & 1 & $2.3 \%$ \\
\hline
\end{tabular}

Out of 43 patients, 14 (32.5\%) patients experienced intraoperative hypotension, $5(11.6 \%)$ developed febrile illness, $27(62.7 \%)$ required ICU care. The mean hospital stay of the patients <10days were $11(25.5 \%)$, >10days were $26(60.4 \%)$ patients. This table shows the associated maternal morbidity with peripartum hysterectomy. Although peripartum hysterectomy is a lifesaving procedure, it is associated with significant morbidity. Table 5 illustrates the complications patients' experienced following hysterectomy. None of the 43 patients required re-laparotomy, $13(30.2 \%)$ patients went into DIC, $5(11.6 \%)$ experienced bladder injury due to involvement of bladder along the rupture of uterus ,repair done simultaneously during hysterectomy, 1 (2.3\%) patient developed vesicovaginal fistula post-operatively. $6(13.9 \%)$ patients who underwent emergency peripartum hysterectomy died during post-operative period. Maternal mortality was $13.9 \%$ in the study. $7(16.2 \%)$ patients underwent an associated procedure for control of haemorrhage -bilateral internal iliac artery ligation.

Table 4: Observations.

\begin{tabular}{|ll|l|}
\hline Observation & & $\%$ \\
\hline Intraoperative hypotension & 14 & $32.5 \%$ \\
\hline Febrile illness & 5 & $11.6 \%$ \\
\hline ICU admission & 27 & $62.7 \%$ \\
\hline $\begin{array}{l}\text { Mean hospital stay } \\
\text { <10days }\end{array}$ & \\
>10days & 11 & $25.5 \%$ \\
\hline
\end{tabular}

Table 5: Complications noted in the study.

\begin{tabular}{|ll|}
\hline Complications & Emergency hysterectomies \\
\hline DIC & $13(30.2 \%)$ \\
\hline Injury to the bladder & $5(11.6 \%)$ \\
\hline Death & $6(13.9 \%)$ \\
\hline Vesicovaginal fistula & $1(2.3 \%)$ \\
\hline
\end{tabular}

One patient was second gravid with central placenta previa, underwent caesarean section for the same, also underwent subtotal hysterectomy due to uncontrollable bleeding from the placental bed, patient expired intraoperative due to irreversible shock. One patient delivered by operative vaginal delivery, developed atonic PPH, which did not respond to conservative management, underwent hysterectomy, died on the same post-operative day due to irreversible shock following massive blood loss. 4 patients expired post-operatively as a consequence of DIC.

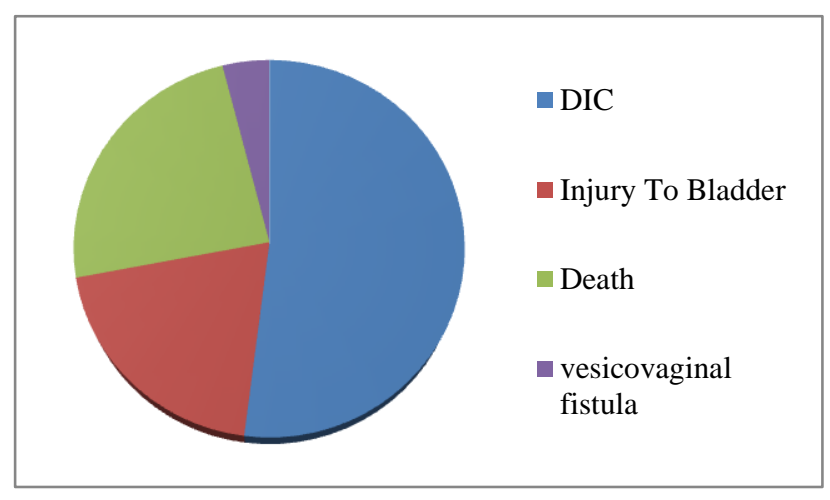

Figure 7: Complications noted in the study.

\section{DISCUSSION}

Emergency peripartum hysterectomy is a lifesaving procedure of choice in cases of intractable hemorrhage and catastrophic rupture of uterus. ${ }^{9}$ It is an unequivocal marker of severe acute maternal morbidity. It is associated with high index of maternal mortality and morbidity.

In developed countries, the reported incidence of emergency hysterectomy is below $0.1 \%$ of the total normal deliveries performed, while in developing countries, the incidence rates are as high as 1-5/ 1000 of all the deliveries performed. The incidence in the present study is 1.4 per 1000 deliveries. The primary reason for this higher incidence is due to the fact that our hospital is a referral centre to most of the primary health care centres in surrounding rural areas. Majority of the patients are unbooked, and deliver outside the health facilities unsupervised or poorly supervised and are referred in a deteriorated state.

The main indications for peripartum hysterectomy in developed countries are uterine atony and abnormal placentation, where as in developing countries, it was rupture of uterus and atony of uterus. ${ }^{10}$ The most common causes of EPH in our study are atonic uterus, rupture uterus of unscarred and scarred uterus. Uterine rupture remains one of the serious obstetric complications even in modern obstetrics. ${ }^{11}$ Lack of health information, illiteracy, poor antenatal care, poverty, home delivery by birth attendants, delay in referrals all contribute to uterine rupture. Injudicious use of oxytocin and trial of labour was the common cause, whereas prolonged obstructed labour was the second common cause. Prevalence in our study is $47 \%$. In this study 16 women underwent EPH for 
rupture uterus, scarred and unscarred. 4 patients had bladder injury and one patient developed vesicovaginal fistula.

\section{CONCLUSION}

Rate of EPH is high in our institution with poor maternal \& foetal outcomes. The incidence in this part of Karnataka was found to be significantly high due to referral cases from neighboring 5 government districts hospitals. hence only proper awareness, timely referral, restricted use of prostaglandins as inducing agents in hospitals not having facilities for C-section and correction of anemia are the key factors to be addressed to this part of the state.

Improvement in female literacy levels, prevalence of contraception, increase the number of women receiving antenatal care and giving birth in hospital delivery facilities supervised by skilled care providers can contribute to reduction in maternal morbidity and mortality. Women who are at high risk for primary postpartum haemorrhage should book for antenatal care and deliver in specialized health facilities.

Funding: No funding sources

Conflict of interest: None declared

Ethical approval: Not required

\section{REFERENCES}

1. Christopoulos P, Hassiakos D, Tsitoura A, Panoulis K, Papadias K, Vitoratos N. Obstetric hysterectomy.A review of cases over 16 years. J Obstet Gynecol. 2011;31(2):139-141.

2. Machado LSM. Emergency peripartum hysterectomy: Incidence, indications, risk factors and outcome. N Am J Med Sci. 2011;3(8):358-61.
3. Yalinkaya A, Guzel AI, Kangal K. Emergency Peripartum Hysterectomy: 16-year Experience of a Medical Hospital. J Chin Med Assoc. 2010;73:360-3.

4. Wani RV, Abu-Hudra NMS, Al-Tahir SI. Emergency Peripartum Hysterectomy : A 13 year review in tertiary centre in Kuwait. The Journal of Obstetrics and Gynaecology of India. 2014; 64(6):403-8.

5. Najam R, Bansal P, Sharma R, Agarwal D. Emergency Obstetric Hysterectomy: A Retrospective Study At A Tertiary Care Hospital. Journal of Clinical and Diagnostic Research. 2010 [cited: 2010 August 25]; 4:2864-2868.

6. Montufar-Rueda C, Rodriguez L, Jarquin JD, Barboza A, Bustillo MC, Marin F, et al. Severe postpartum hemorrhage from uterine atony: a multicentric study. J Pregnancy. 2013;525914.

7. Cengiz H, Yaşar L, Ekin M, Kaya C, Karakaş S. Management of intractable postpartum hemorrhage in a tertiary centre- A 5 year experience. Niger Med J. 2012;53(2):85-8.

8. Victoria YKC, William WK. Uterine compression sutures for management of severe postpartum hemorrhage: 5 year audit. Hong Kong Med J. 2014;20:113-20.

9. Anuradha C, Vani JY, Aruna V. Emergency peripartum hysterectomy - one year study in labour ward Obstetrics and Gynaec department Guntur Medical College, Guntur. (2014). IOSR Journal of Nursing and Health Science (IOSR-JNHS). 2014;4(2)Ver. II:26-8.

10. Pandher K, Sehgal DA, Aggarwal N. Frequency, indications and maternal outcome in obstetric hysterectomy in a tertiary care centre in India." JK Science. 2015;17(1):8-12.

11. Abha S, Shrivastava C. Uterine Rupture: Still a Harsh Reality. The Journal of Obstetrics and Gynecology of India. 2015;65(3):158-161.

Cite this article as: Kittur S, Swetha D. Emergency peripartum hysterectomy- a study in tertiary care centre and medical college in Hubli, North Karnataka, India. Int J Reprod Contracept Obstet Gynecol 2016:5:1097-1101. 